\section{The Length of the Juvenile Period in Olive as Influenced by Vigor of the Seedlings and the Precocity of the Parents}

\author{
Fernando Santos-Antunes \\ Departamento de Olivicultura, Elvas, Portugal
}

Lorenzo León and Raúl de la Rosa'
CIFA Alameda del Obispo, IFAPA, Avda. Menéndez Pidal s/n, Córdoba, 14008,
Spain

Juán Alvarado, Ana Mohedo, Isabel Trujillo, and Luis Rallo

Departamento de Agronomía, Universidad de Córdoba, Avda. Menéndez Pidal s/n, 14008, Córdoba, Spain

Additional index words. breeding, forced growth, juvenility, Olea europaea

\begin{abstract}
A first attempt to determine the effect of vigor and parents on the length of the juvenile period of olive seedlings is here reported. Vigor seems to have a significant influence on the percentage of flowering seedlings, especially in the first 2 years of bearing. The different parents used have produced differences in the juvenile period of their descendants. A correspondence between the length of the unproductive period of the parents and the length of the juvenile period that they transmit to their descendants has been observed. The seedling forcing growth protocol described here has been able to produce flowering seedlings 28 months after germination, with $>93 \%$ of seedlings flowering 65 months after germination.
\end{abstract}

The length of the juvenile period has been traditionally one of the main drawbacks of fruit tree breeding(Hackett, 1985; Visser and Schaap, 1967). In fact, "a long juvenile period tries breeder's patience and weights on his orchard budget" (Visser et al., 1976). Fruit characteristics can only be evaluated once flowering and fruiting have been established; therefore, the cost of cultivar improvement is in almost direct proportion to the length of the juvenile period (Hansche, 1983).

Two of the main factors reported to influence the length of the juvenile period are the parents and the seedling vigor. The adequate choice of parents has demonstrated to be of great importance for the reduction of juvenile period in apple, pear (Bell and Zimmerman, 1990; Visser, 1976) and peach (Hansche, 1986), since the heritability of this character seems to be predominantly additive. In this sense, new strategies of associations between molecular markers and genes controlling the length of the juvenile period have also been attempted (Liebhard et al., 2003). Vigor has been considered very important for the beginning of flowering of seedlings in fruit breeding programs (Wareing, 1959; Zimmerman, 1972). Fruit tree species need a minimum vegetative growth and height to reach the adult phase and then the ability to produce flowers (Visser, 1965, 1970; Zimmer-

Received for publication 3 Nov. 2004. Accepted for publication 16 Dec. 2004. This research was supported by Projects OLI96-2184, CAO97-001C12-11 and CAO99-008 of the Spanish Ministry of Agriculture, Food and Fisheries.

${ }^{1}$ To whom reprint requests should be addressed; e-mail raul.rosa@juntadeandalucia.es. man, 1971). A negative relation between vigor and juvenile period has been reported in apple (Visser, 1970; Way, 1971) and pear (Zimmerman, 1977).

In olive, the juvenile period is longer than in other fruit tree species (Humanes et al., 1967; Natividade, 1956; Rugini, 1990). Bellini(1993) showed that only $20 \%$ of seedlings from crosses among different olive cultivars reach flowering 12-13 years after seed germination. This may be a reason why there have been so few efforts to produce new olive cultivars able to replace the centennial ones cultivated today (Bellini et al., 2002; Lavee et al., 2003), despite of the social and economical importance of olive growing in the Mediterranean Basin. Few attempts of studying the juvenile period in olive have also been reported (Lavee et al., 1996). In 1991, an olive breeding program started in Córdoba, Spain (Rallo, 1995). One of the objectives of this program was to shorten the juvenile period of olive seedlings, thus allowing agronomic selection in a short period of time.

In the framework of this program, the aim of this work was to evaluate the influence of tree size and parents on the length of the juvenile period of olive seedlings, so far not described in the literature.

\section{Material and Methods}

The seedlings used in the present study came from the mentioned olive breeding program of Cordoba. A forcing growth protocol is used, in this program, to shorten the natural long juvenile period of olive. The techniques used here are similar to those reported for apple (Aldwinckle,
1975; Fisher, 1994), crabapple (Zimmerman, 1971) and pecan (Thompson and Grauke, 2003) to reach quickly the minimum size necessary to attain the adult phase.

Crosses, germination of seeds and greenhouse growth. Seedlings from the crosses and selfings of the nine possible combinations of the olive cultivars 'Arbequina', 'Frantoio', and 'Picual', carried out in 1992 and 1993 were used for all the experiments. Crosses were made by applying male pollen to female bagged branches. Naked seeds from fruit, harvested in November of 1992 and 1993 respectively, were stratified in Petri dishes filled up with wetted perlite $(40 \mathrm{~g}$ of perlite and $100 \mathrm{ml}$ of water) at 14 to $15^{\circ} \mathrm{C}$ in the dark for $45 \mathrm{~d}$. Germinated seeds (radicule of the $75 \%$ to $80 \%$ of the seeds longer than $5 \mathrm{~cm}$ ) were grown into 0.3 -L volume pots in growth chamber. After $45 \mathrm{~d}$ of growth, they were transplanted into 9-L volume plastic pots filled up with a mixture of 2 sand : 1 peat and placed in the greenhouse. To force seedling growth, drip fertirrigation were applied, temperature was controlled $\left(22^{\circ} \mathrm{C}\right.$ on average $)$ and continuous light was ensured with metallic halogen lamps. Also with that purpose, lateral shoots were pinched off when they reach more than $10 \mathrm{~cm}$ long. Shoots inserted in the main stem higher than $160 \mathrm{~cm}$ were left unpruned in order to form the future canopy. This forcing protocol is consequence of previous experiments (Santos-Antunes, 1999).

Field growth. Forced seedlings of the mentioned crosses done in 1992 and 1993 were transplanted into the field in two consecutive years. Thus, there were two trials. In trial 1, seeds from the crosses and selfings of the nine possible combinations of the three olive cultivars were germinated in November 1992 and planted in open field in April 1994, with a total of 288 plants. In trial 2, seeds from all combinations except 'Picual' selfing were germinated in November 1993 and planted in February 1995, with a total of 96 plants. Trees were planted at $1.5 \mathrm{~m}$ distance between trees in a row and 3.5 $\mathrm{m}$ between rows. In trial 1, the lateral shoots were totally pruned up to $160 \mathrm{~cm}$ height from the beginning of plantation. In trial $2,10 \mathrm{~cm}$ of lateral shoots were kept, during the first 2 years of field growth, from 100 to $160 \mathrm{~cm}$ height and then removed. The experimental design was randomized blocks with four replications and eight plants per elementary plot in trial 1 , the same with three replications and four plants per elementary plot in trial 2.

Data analysis. Flowering was evaluated in all the seedlings for the first 4 years after transplanting into the field. Four levels of amount of flowering were recorded: $0=$ absence, $1=$ few, 2 $=$ medium and $3=$ high. This allowed the estimation offlowering index as the average amount of flowering per elementary plot. Trunk girth was recorded, at $1 \mathrm{~m}$ above ground, in November preceding the first four flowerings.

Trunk girth of flowering and non-flowering seedlings was compared for the first 4 years of bearing.

The two trials considered in this study were compared for the mentioned measurements.

Analysis of variancewas performed to test the effect of the female parents on the percentage of 
Table 1. Comparison of trials 1 and 2 for the mean trunk girth, mean percentage of adult seedlings and mean amount of flowering. Standard errors of elementary plot means have been used to calculate differences between means.

\begin{tabular}{|c|c|c|c|c|c|c|}
\hline \multirow{2}{*}{$\begin{array}{l}\text { Months } \\
\text { from } \\
\text { germination }\end{array}$} & \multicolumn{2}{|c|}{$\begin{array}{l}\text { Trunk girth } \\
(\mathrm{cm})\end{array}$} & \multicolumn{2}{|c|}{$\begin{array}{c}\text { Adult } \\
\text { seedlings }^{\mathrm{z}}(\%)\end{array}$} & \multicolumn{2}{|c|}{$\begin{array}{l}\text { Amount of } \\
\text { flowering }\end{array}$} \\
\hline & 1 & 2 & 1 & 2 & 1 & 2 \\
\hline 29 & $3.7 \pm 0.1$ & $5.8 \pm 0.2$ & $0.8 \pm 0.1$ & $15.8 \pm 0.5$ & $0.03 \pm 0.01$ & $0.39 \pm 0.08$ \\
\hline 41 & $8.4 \pm 0.2$ & $12.3 \pm 0.4$ & $51.5 \pm 0.5$ & $53.3 \pm 0.6$ & $0.73 \pm 0.08$ & $0.52 \pm 0.05$ \\
\hline 53 & $15.0 \pm 0.3$ & $18.8 \pm 0.5$ & $78.8 \pm 0.4$ & $91.6 \pm 0.4$ & $0.63 \pm 0.04$ & $1.80 \pm 0.15$ \\
\hline 65 & $18.6 \pm 0.3$ & $24.9 \pm 0.6$ & $93.4 \pm 0.2$ & $98.7 \pm 0.2$ & $1.92 \pm 0.11$ & $1.45 \pm 0.12$ \\
\hline
\end{tabular}

${ }^{2}$ Data has been transformed for calculate standard errors using arcsine of root square and back-transformed to be presented in the table.

Trial 1

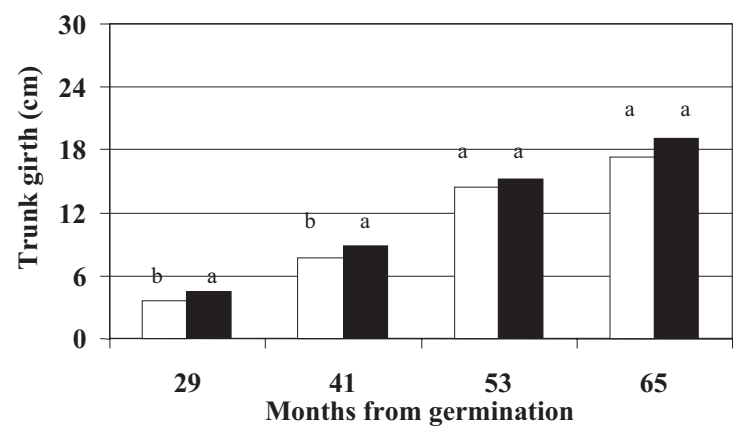

Trial 2

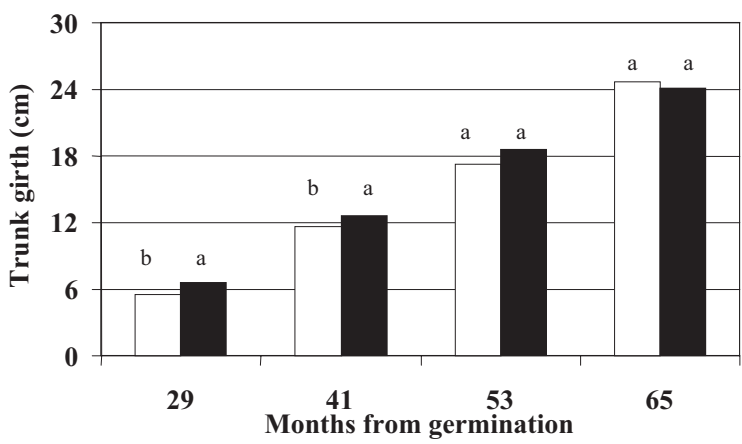

Fig. 1. Comparison between flowering seedlings for first time (black) and not flowering seedlings (white), for the mean of trunk girth $(\mathrm{cm})$ measured in November before flowering. Data are presented for the first four flowering seasons and in the two trials studied. Different letters indicates significant differences (LSD, $p<0.05$ ) within months from germination.

adult seedlings per elementary plot (previously transformed by arcsine of root square) and on the flowering index. Male effect was not analyzed as there were evidences of contamination in the crosses performed (De la Rosa et al., 2004).

\section{Results and Discussion}

In the two trials evaluated, the first flowering occurred 29 months after germination and $>93 \%$ of the seedlings flowered (reached the adult phase) 65 months after germination (Table 1). The second trial showed a higher mean vigor the 4 years studied. This was correlated with a higher percentage of seedlings reaching the adult phase. Although the data of more trials would be needed to confirm this correlation, these data are consistent with similar results reported in pear (Zimmerman, 1977). The results obtained indicate that the seedling forcing growth proto- col here reported facilitates olive breeding, since it permits to have a relative reduced generation time. In fact, the juvenile period could take $\geq 12$ years in normal field conditions (Bellini, 1993). Lavee et al.(1996) obtained firstflowering 4 years after germination by forcing growth in open field. Here we were able to reduce this period to 29 months by greenhouse forcing growth. Similar methodologies have been used in several fruit species, as mentioned in materials and methods.

Mean trunk girth of seedlings flowering for the first time was significantly higher than of nonflowering seedlings, in the first 2 years of flowering (Fig. 1). This occurred in the two trials evaluated. This indicates that there is a consistent relation between vigor and the length of the juvenile period in olive, as has been previously reported in apple (Visser, 1970; Way, 1971), and pear (Zimmerman, 1977). No significant correlation was found between trunk girth and amount of flowering (data not shown).

Female parent genotype also influenced the length of the juvenile period, with 'Arbequina' and 'Picual' producing seedlings with shorter average juvenile period than 'Frantoio'(Fig. 2). Differences were slightly more evident in trial 1 than in trial 2 maybe because of the higher number of seedlings in the first one. Female influence on the flowering index was more apparent, with 'Arbequina' producing higher flowering index than 'Picual' and this higher than 'Frantoio' (Fig. 3). In trial 2 no differences were found between 'Arbequina' and 'Picual' seedlings maybe due, again, to the lower number of seedlings evaluated.

The effect of the parents on the length of the juvenile period has been previously reported for other fruit tree species (Bell and Zimmerman, 1990; Hansche, 1986; Schmidt, 1976; Visser, 1976). Furthermore, an average reduction in the juvenile period may be expected in successive selection cycles, as has been suggested in other species (Hansche, 1986; Visser, 1976), or, at least, an increase in the percentage of adults bearing seedlings the first year of flowering. That would facilitate the selection of new olive cultivars from cross breeding avoiding the long juvenile period of seedlings.
There is also a correspondence between the length of the unproductive period of the three cultivars used as parents ('Arbequina' $<$ 'Picual' $<$ 'Frantoio') and the length of the juvenileperiod that they transmit to their seedlings. 'Arbequina' confers on the seedlings a short juvenile period, while 'Frantoio' does the opposite. This suggests a relationship between these two characteristics. This relation between the length of the juvenile period of seedlings and the unproductive period of the parenthas previously been reported in pear (Visser, 1965; Vondracek, 1976). This makes the selection of parents with short unproductive period of double interest: the generation time in the breeding program will be shorter and the new cultivars released should have a shorter unproductive period. This is a very interesting character in olive where the length of the unproductive period in most cultivars is usually longer than 4 to 5 years (Del Río and Caballero, 1994).

In conclusion, the results obtained indicate that both vigor and parents seems to have influence on the occurrence of the first flowering, i.e., on the length of the juvenile period. The forcing of the seedling growth in the greenhouse jointly with the adequate use of parents, as 'Arbequina', can shorten considerably the length of the juvenile period in olive and thus facilitate the progress of the breeding programs.

\section{Literature Cited}

Aldwinckle, H.S. 1975. Flowering of apple seedlings 16-20 months after germination. HortScience 10:124-126.

Bell, R.L. and R.H. Zimmerman. 1990. Combining ability analysis of juvenile period in apple. HortScience 25:1425-1427.

Bellini,E. 1993. Behaviour of some genetic characters in olive seedlings obtained by cross-breeding. Acta Hort. 317:197-208.

Bellini, E., E. Giordani, M.V. Parlati, and S. Pandolfi. 2002. Olive genetic improvement: Thirty years of research. Acta Hort. 586:105-108.

De la Rosa, R., C.M. James, and K.R. Tobutt. 2004. Using microsatellites for paternity testing in olive progenies. HortScience 39:351-354.

Del Río, C. and J.M. Caballero. 1994. Preliminary agronomical characterization of 131 cultivars introduced in the olive germplasm bank of Cordoba in March 1987. Acta Hort. 356:110-115.

Fisher, C. 1994. Shortening of the juvenile period in apple breeding, p. 161-164. In: H. Schmidt, and M. Kellerhals (eds.). Progress in temperate fruit breeding. Kluwer Academic Publ., Dordrecht, The Netherlands.

Hackett, W.P. 1985. Juvenility, maturation and rejuvenation in woody plants. Hort. Rev. 7:109-155.

Hansche, P.E. 1983. Response to selection, p. 154-171. In: J.N. Moore and J. Janick (eds.) Methods in fruit breeding. Purdue Univ. Press, West Lafayette, Ind.

Hansche, P.E. 1986. Heritability of juvenility in peach. HortScience 21:1197-1199.

Humanes J., J. Ferreira, and P. Fernandez-Bolaños. 1967. Selección de nuevas variedades de olivo. Port. Acta Biol/Ser. 185-194.

Lavee, S., N. Avidan, A. Haskal, and A. Ogrodovich. 1996. Juvenility period reduction in olive seedlings - A tool for enhancement of breeding. Olivae 60:33-41.

Lavee, S., N. Avidan, and Y. Meni. 2003. 'Askal', a new high-performing oil variety for intensive and super-intensive olive orchards. Olivae 97:53-59. 
Trial 1

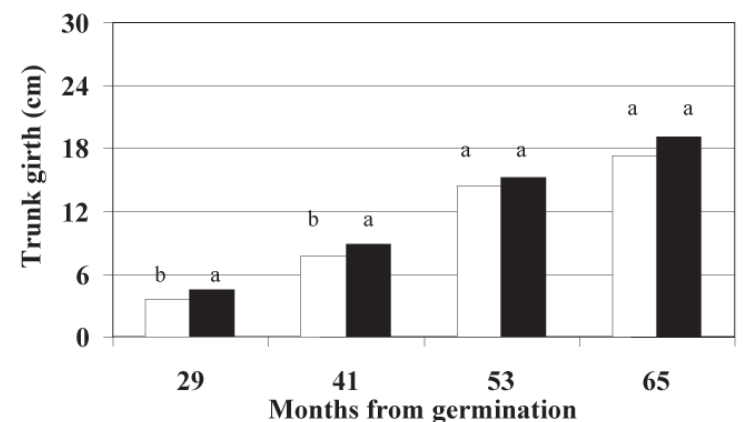

Trial 2

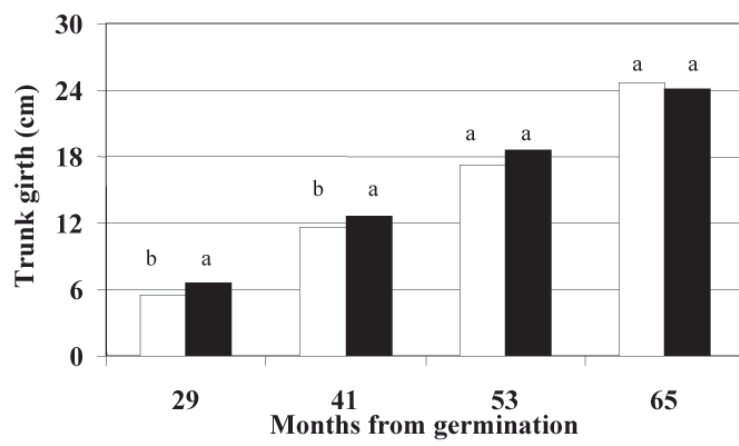

Fig. 2. Influence of the female parent ('Arbequina' = white, 'Frantoio' = gray, 'Picual' = black) on the percentage of adult seedlings per elementary plot in plantation 1 and 2. Different letters indicates significant differences for angular transformed data (LSD, $p<0.05)$ within months from germination.

Trial 1

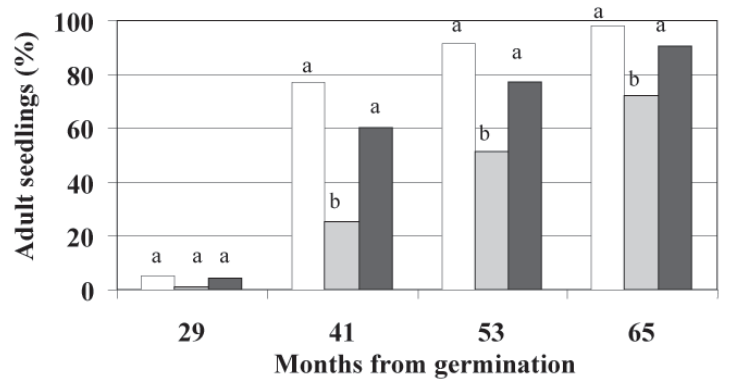

Trial 2

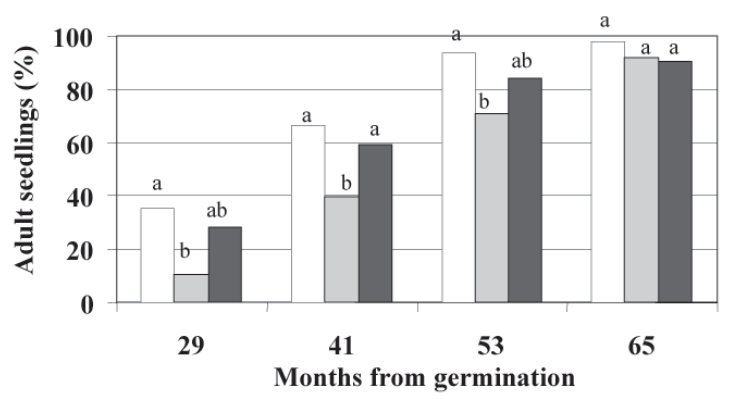

Fig. 3. Influence of the female genitor ('Arbequina' = white, 'Frantoio' = gray, 'Picual' = black) on the mean flowering index per elementary plot in trials 1 and 2. Different letters indicates significant differences (LSD, $p<0.05$ ) within months from germination.
Liebhard, R., M. Kellerhals, W. Pfammatter, M. Jertmini, and C. Gessler. 2003. Mapping quantitative physiological traits in apple (Malus $\times$ domestica Borkh.). Plant Mol. Biol. 52:511-526.

Natividade, J.V. 1956. Juvenilidade en Olea europaea L. Agronomia Lusitania 19:145-159.

Rallo, L. 1995. Selection and breeding of olive in Spain. Olivae 59:46-53

Rugini, E. 1990. In vitro culture of the olive: An overview of the present scientific status. Acta Hort. 286 93-96.

Santos-Antunes, F. 1999. Acortamiento del periodo juvenil en olivo mediante técnicas de forzado y elección de genitores. PhD thesis. Univ. Cordoba, Spain.

Schmidt, H. 1976. On the inheritance of the length of the juvenileperiod in interespecific Prunus hybrids. Acta Hort. 56:229-234.

Thompson, T.E. and L.J. Grauke. 2003. Pecan tree growth and precocity. J. Amer. Soc. Hort. Sci. 128:63-66.

Visser, T. 1965. On the inheritance of the juvenile period in apple. Euphytica 14:125-134.

Visser, T. 1970. The relation between growth, juvenile period and fruiting of apple seedlings and its use to improve breeding efficiency. Euphytica 19:293-302.

Visser, T. 1976. A comparison of apple and pear seedlings with reference to the juvenile period. II. Mode of inheritance. Euphytica 25:339-342.

Visser, T. and A.A. Schaap. 1967. Pre-selection for juvenile period, flowering and picking time in apple seedlings. Euphytica 16:109-121.

Visser, T., J.J. Verhaegh, and D. de Vries. 1976. A comparison of apple and pear seedlings with reference to the juvenile period. I. Seedling growth and yield. Euphytica 25:343-351.

Vondracek, J. 1976. Independence of the length of the juvenile period of pear hybrids on the beginning of fertility of the parent cultivars. Acta Hort. 56:225-228.

Wareing,P.F. 1959. Problems of juvenility and flowering in trees. J. Linnean Soc. (Bot.) 56:282-289.

Way, R.D. 1971. Hastening the fruiting of apple seedlings. J. Amer. Soc. Hort. Sci. 96:384-389.

Zimmerman, R.H. 1971. Flowering in crabapple seedlings: Methods of shortening the juvenile phase. J. Amer. Soc. Hort. Sci. 96:404-411.

Zimmerman, R.H. 1972. Juvenility and flowering in woody plants: A review. HortScience 7:447-455.

Zimmerman, R.H. 1977. Relation of pear seedling size to length of the juvenile period. J.Amer. Soc. Hort. Sci. 102:443-447. 